\title{
Selection of cypermethrin resistance in mosquito Culex pipiens larvae in Assiut, Egypt
}

\author{
Abouelkassem Sh. ${ }^{1}$, Korrat R. A. A. ${ }^{*}$, Korrat E. E. E. ${ }^{2}$ \\ ${ }^{I}$ Plant Protection Department, Faculty of Agriculture, Al-Azhar University, Assiut, Egypt \\ ${ }^{2}$ Plant Protection Department, Faculty of Agriculture, Al-Azhar University, Cairo, Egypt
}

\begin{abstract}
To induce cypermethrin resistance in Culex pipiens larvae, about $200004^{\text {th }}$ instar larvae of Cx. pipiens were collected from Assiut field and exposed to cypermethrin selection pressure for fifteen generations using dipping method. This study revealed that the resistance ratio $\left(R_{50}\right)$ of the parent strain $\left(G_{0}\right)$ was 14.49 -fold as compared with susceptible strain. This $\mathrm{RR}_{50}$ value increased gradually from each generation to the next one as a result of selection pressure with cypermethrin. The regression line for cypermethrin against the parent field strain showed slope value 2.38 which indicate a moderate level of heterogeneity of parent strain to cypermethrin. The first five generations during the course of cypermethrin selection showed that resistance ratio $\left(R_{50}\right)$ was increased gradually from one generation to the next (The $R_{50}$ increased from 14.49-fold in $\mathrm{G}_{0}$ to 135.40 -fold resistance in $\mathrm{G}_{5}$ ). By the $6^{\text {th }}$ generation, the rate of resistance development to cypermethrin was fairly rapid where; the $\mathrm{RR}_{50}$ to cypermethrin increased from 135.40-fold in $\mathrm{G}_{6}$ to 272.00 -fold resistance in $\mathrm{G}_{11}$. With the beginning of the $12^{\text {th }}$ generation, the development of resistance to cypermethrin was increased very slowly during the last four generations from 279.92 -fold in $\mathrm{G}_{12}$ to 295.52 -fold resistance in $\mathrm{G}_{15}$ (plateau phase). Finally, the slope values were volatile until the eleventh generation $(2.38-3.63)$ and then relatively proven in the last four generations $(4.55-4.52)$. This is evidence of increasing homogeneity of selected strain in the last five generations.
\end{abstract}

Keywords: insecticides, cypermethrin, resistance, Culex pipiens, mosquito, selection.

*Corresponding author: Korrat R. A. A., 


\section{Introduction}

The major mosquito vectors span the Culex, Aedes, and Anopheles genera. Culex $s p$. is the major vector of filariasis and Japanese encephalitis, Aedes of dengue and dengue hemorrhagic fever, and Anopheles of malaria. Culex quinquefasciatus is a member of the $C x$. pipiens complex Linnaeus and one of the main subspecies found in Africa (Drummond et al., 1951; Subra, 1981). Culex quinquefasciatus (Diptera: Culicidae) is widely distributed in tropical and subtropical areas and is the most important vector of filarial parasite Wuchereria bancrofti, although Anopheles gambiae s.l and An. funestus also play a role in selected areas (Guillemaud et al., 1998; Maxwell et al., 1990). Insecticides play a pivotal role in controlling major vectors of diseases such as mosquitoes. For the last 70 years, pesticides have been widely used to control insects. The wide use of organic insecticides to control medically and agriculturally important pest species has been a powerful agent of selection in natural populations of many insect species which have developed various degrees of resistance (Georghiou and LagunesTejeda, 1991). The resistance problems continued with the switch to deferent groups of insecticides such as organophosphates, carbamates and pyrethroids. Focal spraying limits the insecticides of choice largely to pyrethroids due to the speed of control required to protect the occupant of the safety margin needed for insecticides used in such close contact with people. The development of pyrethroid resistance in
An. gambiae is particularly important given the recent emphasis by the WHO and other organizations on the use of pyrethroid-impregnated bednets for malaria control. Current strategies for malaria vector control rely heavily on chemical means for both the indoor residual spraying (IRS) of insecticide and the use of insecticide-treated nets (ITNs) (World Health Organization (WHO), 2013). Use non-pyrethroid insecticides if Long-lasting Insecticidal Nets (LLIN) and Indoor Residual Spraying (IRS) are to be deployed together in the same geographical location in order to reduce selection pressure for pyrethroid resistance (WHO, 2014). The dynamics of pesticide resistance genes in natural populations is dependent on the classical evolutionary factors: mutation, migration, drift and/or selection. For the mosquito $C x$. pipiens, it has been shown that mutation is a limiting factor (Raymond and Marquine, 1994). Resistance genes are obviously advantageous in treated areas, so that their frequencies increase with selection. Until recently, the evolution of resistance could only be studied by bioassays, which measure the overall result of resistance genes present in a population. Unfortunately, the extensive use of insecticides has led to the selection of insecticide resistance in malaria vectors. To date, only a limited number of insecticide chemical classes are available for mosquito control. Only four classes of insecticide (Carbamates, organophos-phates, organochlorines and pyrethroids) are available for IRS, whereas the use of LLINs depends exclusively on pyrethroids. The two major causes of insecticide resistance 
increasing metabolic detoxification and decreasing target site sensitivity (Hemingway and Ranson, 2000). In metabolic detoxification, the insecticide is prevented from reaching its site of action by detoxification enzymes. Decreased target site sensitivity, by contrast, reduces the rate at which the insecticide binds to its target site. The first case of pyrethroid resistance was recorded in West Africa more precisely in Côte d'Ivoire (Elissa et al., 1993). Many other cases have been described in Benin (Chandre et al., 1999), in Burkina Faso (Chandre et al., 1999) and in Mali (Fanello et al., 2003). In West Africa, A. gambiae resistance to the four major classes of insecticides available for public health has been reported (Chandre et al., 1999; Elissa et al., 1993; Fanello et al., 2003). However, the success of control methods is threatened by resistance to the main insecticides such as pyrethroids in malaria vectors.

\section{Materials and Methods}

\subsection{Insecticide}

The toxicant used in the present experiment was the insecticide Cypermethrin; Ripcord (10\% E.C) (Shell International Chemical CO.).

\subsection{Insect strains}

Two strains of $C x$. pipiens were used in this study as follow:

\subsubsection{Susceptible strain (S-strain)}

The susceptible strain used in the present study was brought from the Institute of Veterinary and Medical Insects in Cairo, Egypt which reared in the laboratory for 7 years away from any insecticidal pressure.

\subsubsection{Parent field strain (F-strain)}

The field strain was wild larvae of $C x$. pipiens which was collected in season of abundance from Faculty of Agriculture Farm, Al-Azhar University, Assiut, Egypt.

\subsection{Collecting and rearing techniques}

Two strains transferred to the laboratory of Plant Protection Department, Faculty of Agriculture, Assuit University, Assiut, Egypt and reared under laboratory conditions according to the method recommended by WHO (1981).

\subsection{Toxicity studies}

2.4.1 Laboratory induction of Cypermethrin resistant strain (CYP-Rstrain) of Cx. pipiens larvae

A part of the field parent strain was selected with technical cypermethrin according to the method recommended by WHO (1981). The fourth instar larvae of the parent strain $\left(\mathrm{G}_{0}\right)$ and successive generations was used in this trail. The $\mathrm{LC}_{50}$ values for the same generation were used as the selective pressure of Cypermethrin for each successive generation. The selection pressure was 
applied using the dipping method. About 3000 to $40004^{\text {th }}$ instar larvae were selected for each generation and larvae survived after treatment were reared under standardized laboratory conditions. Emerged adults constituted the parents of succeeding generation. Selection was carried out for every generation throughout successive fifteen generations. $\mathrm{LC}_{50}$ value of Cypermethrin in each generation was determined as mentioned before. The resistance ratio for the Cypermethrin in each generation at $\mathrm{LC}_{50}\left(\mathrm{RR}_{50}\right)$ was calculated as:

$\mathrm{RR}_{50}=\mathrm{LC}_{50}$ of the tested generation $/ \mathrm{LC}_{50}$ of S-strain

(Robertson et al., 2007).

\section{Results and Discussion}

To induce cypermethrin resistance in $C x$. Pipiens larvae, about $200004^{\text {th }}$ instar larvae of $C x$. pipiens were collected from the field and exposed to cypermethrin selection pressure for fifteen generations using dipping method. $\mathrm{LC}_{50}$ values (as $\mu \mathrm{g} / \mathrm{L}$ ), confidence limits of $\mathrm{LC}_{50}$ and slope values were obtained for each generation. Each generation was selected by cypermethrin at a concentration equivalent to the $\mathrm{LC}_{50}$ value of this generation. Resistance ratio $\left(\mathrm{RR}_{50}\right)$ was calculated as mentioned above. All obtained results are recorded in Table (1) and Figure (1). Results in Table (1) revealed that the resistance ratio $\left(\mathrm{RR}_{50}\right)$ of the parent strain $\left(\mathrm{G}_{0}\right)$ was 14.4-fold. This $R_{50}$ value increased gradually from each generation to the next one as a result of selection pressure with cypermethrin. The $\mathrm{RR}_{50}$ values were $14.49,28.65$, 47.83, 56.16, 73.29, 135.40, 192.96, 214.64, 228.87, 234.90, 243.68, 272.00, $279.92,283.25,291.57$ and 295.52 for $\mathrm{G} 0, \mathrm{G}_{1}, \mathrm{G}_{2}, \mathrm{G}_{3}, \mathrm{G}_{4}, \mathrm{G}_{5}, \mathrm{G}_{6}, \mathrm{G}_{7}, \mathrm{G}_{8}, \mathrm{G}_{9}$, $\mathrm{G}_{10}, \mathrm{G}_{11}, \mathrm{G}_{12}, \mathrm{G}_{13}, \mathrm{G}_{14}$ and $\mathrm{G}_{15}$, respectively. Results in Table 1 showed that the slope values for the corresponding generations were 2.38, $3.17,3.29,3.07,4.44,3.33,3.03,3.23$, $3.29,3.63,3.63,3.63,4.55,4.67,4.76$ and 4.52 , respectively. From the abovementioned results, it could be concluded that: First, the filed parent strain in the present study exhibited low level of resistance to cypermethrin (14.49). This may be due to a large portion of the filed population avoid exposure to insecticides, providing susceptible individuals for repopulation of cypermethrin resistant Cx. Pipiens mosquitoes to become 295.52-fold resistance after selection with cypermethrin for 15 generations. Also, the regression line for cypermethrin against the parent field strain showed slope value 2.38 which indicates a moderate level of heterogeneity of the parent strain to cypermethrin. Second, the results in Table 1 and Figure 1 revealed that in the first five generations during the course of cypermethrin selection, the resistance level $\left(\mathrm{RR}_{50}\right)$ was increased gradually from one generation to the next (The $\mathrm{RR}_{50}$ increased from 14.49-fold in $\mathrm{G}_{0}$ to 135.40-fold resistance in $G_{5}$ ). By the $6^{\text {th }}$ generation, the rate of resistance development to cypermethrin 
was fairly rapid where the $R_{50}$ to cypermethrin increased from 135.40-fold in $\mathrm{G}_{6}$ to 272.00 -fold resistance in $\mathrm{G}_{11}$. With the beginning of the $12^{\text {th }}$ generation, the development of resistance to cypermethrin was increased very slowly during the last four generations from 279.92-fold in $\mathrm{G}_{12}$ to 295.52-fold resistance in $\mathrm{G}_{15}$ (plateau phase). Finally, the slope values were volatile until the eleventh generations $(2.38-3.63)$ and then relatively proven in the last four generations $(4.55-4.52)$. This is evidence of increasing homogeneity of the selected strain in the last five generations.

Table (1): Toxicity of Cypermethrin to the $4^{\text {th }}$ instar larvae of Culxe pipiens in relatively successive selected generations for detecting resistance level.

\begin{tabular}{|c|c|c|c|c|c|}
\hline \multirow{2}{*}{ Generation } & \multirow{2}{*}{$\begin{array}{l}\mathrm{LC}_{50} \\
\mathrm{ug} / 1 \\
\end{array}$} & \multicolumn{2}{|c|}{$95 \%$ confidence limits } & \multirow{2}{*}{ Slope $\pm \mathrm{SE}^{\mathrm{a}}$} & \multirow{2}{*}{$\mathrm{R} \mathrm{R}_{50^{\mathrm{b}}}$} \\
\hline & & Lower & Upper & & \\
\hline$\overline{\mathrm{P}^{\mathrm{c}}}$ & 1.492 & 1.006 & 1.885 & $2.38 \pm 0.47$ & 14.49 \\
\hline 1 & 2.951 & 2.305 & 3.511 & $3.17 \pm 0.82$ & 28.65 \\
\hline 2 & 4.927 & 4.192 & 5.864 & $3.29 \pm 0.84$ & 47.83 \\
\hline 3 & 5.784 & 5.020 & 6.686 & $3.07 \pm 0.60$ & 56.16 \\
\hline 4 & 7.549 & 6.872 & 8.464 & $4.44 \pm 0.76$ & 73.29 \\
\hline 5 & 13.946 & 11.828 & 16.303 & $3.33 \pm 0.58$ & 135.40 \\
\hline 6 & 19.875 & 16.613 & 23.602 & $3.03 \pm 0.55$ & 192.96 \\
\hline 7 & 22.108 & 17.778 & 26.295 & $3.23 \pm 0.76$ & 214.64 \\
\hline 8 & 23.574 & 19.418 & 27.454 & $3.29 \pm 0.60$ & 228.87 \\
\hline 9 & 24.195 & 20.445 & 27.827 & $3.63 \pm 0.62$ & 234.90 \\
\hline 10 & 25.099 & 18.932 & 29.400 & $3.63 \pm 0.85$ & 243.68 \\
\hline 11 & 28.016 & 24.135 & 32.385 & $3.63 \pm 0.61$ & 272.00 \\
\hline 12 & 28.832 & 25.539 & 32.514 & $4.55 \pm 0.67$ & 279.92 \\
\hline 13 & 29.175 & 25.921 & 32.828 & $4.67 \pm 0.68$ & 283.25 \\
\hline 14 & 30.032 & 25.964 & 33.614 & $4.76 \pm 0.75$ & 291.57 \\
\hline 15 & 30.439 & 26.165 & 34.520 & $4.52 \pm 0.88$ & 295.52 \\
\hline
\end{tabular}

${ }^{\mathrm{a}}=\mathrm{SE}$ : standard error. ${ }^{\mathrm{b}}=\mathrm{RR}_{50}$ : resistance ratio $=\mathrm{LC}_{50}$ of the selected generation /

$\mathrm{LC}_{50}$ of the Susceptible strain. ${ }^{\mathrm{c}}=\mathrm{P}$ : Parent field strain.

From the results in Table (1), develops in an insect population depends cypermethrin resistant strain of $C x$. on many factors but of major importance pipiens from the field parent strain was obtained. The difference in $\mathrm{RR}_{50}$ values among the tested insecticides against $C x$. pipiens larvae in the present study may be due to several factors. According to Kuhr and Dorough (1976) it is suggested that the speed with which resistance is the intensity of selection, the frequency of resistant genotypes in the population, the number of genes involved in conferring resistance, whether the gene expression is dominant or recessive, history of exposure to other toxicant and counteracting effect of natural selection. 
Georghiou and Taylor (1986) reported that resistance does not evolve at the same rate for all organisms that come under selection pressure.

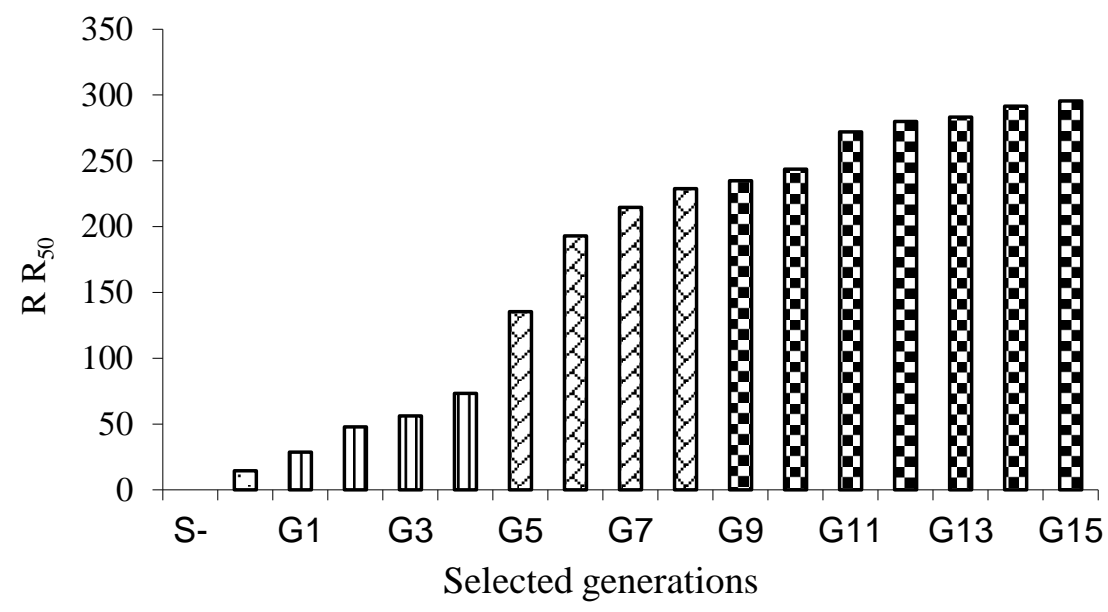

Figure (1): Gradual increase of cypermethrin resistance in $C x$. pipiens larvae treated with cypermethrin at the $\mathrm{LC}_{50}$ values for 15 successive generations. The $\mathrm{R} \mathrm{R}_{50}$ was calculated with reference to susceptible strain.

Even within one species, resistance may develop more rapidly in one population than in another. There are many factors that can influence the rate of resistance to insecticide in the field population. These factors are grouped into three categories depending on whether they concern the genetics of resistance, the biology/ecology of the pest, or the operational control used. Genetic factors can be divided to sub factors: frequency of $\mathrm{R}$ alleles, number of $\mathrm{R}$ alleles, dominance of $\mathrm{R}$ alleles, penetrance, expressivity and interaction of $\mathrm{R}$ alleles, past selection by other chemicals, and extent of integration of $\mathrm{R}$ genome with fitness factors. Biological/ecological factors contain also many sub factors such as generation turnover, offspring per generation, monogamy, polygamy and parthenogenesis, isolation, mobility, migration, monophagy or polyphagy and fortuitous, survival and refugia. The last operational factors contain sub factor, such as chemical nature of pesticide, relationship to earlier used chemicals, persistence of residue and formation, application threshold, selection threshold, life stage(s) selected, mode of application, space-limited selection and alternating selection. Most factors in the first two categories cannot be controlled and the importance of some not even is determined until resistance has already developed. Nonetheless, some factors that influence the evolution of resistance are under man's control, especially those related to the timing and dose of 
insecticide application. The problem is to identify them and determine how their manipulation under existing genetic and biological/ecological constrains may retard the evolution of resistance. It is abundantly clear that merely switching to new insecticides, when the current one is no longer effective cannot continue because of insecticide cross-resistance (Georghiou and Taylor, 1986; Kuhr and Dorough, 1976). Integrated pest management, which will always involve the use of pesticides, is now regarded essential. Recognizing and manipulating factors that influence insecticide resistance and retard resistance development should be an integral part in any resistance management strategy. The practice of using insecticide rotations as a strategy to avoid the development of resistance requires the deployment of insecticide classes over time to reduce selection pressure for resistance to any single class. The conditions required for rotations to delay selection for resistance are that resistance alleles are deleterious in the absence of insecticide selection and that residues of the selecting insecticide have decayed to a point at which they no longer select (Denholm and Rowland, 1992). In the present study, $R_{50}$ value became 295.52 in $\mathrm{G}_{15}$ as compared with 14.49 in $\mathrm{G}_{0}$ indicated that cypermethrin resistance have developed rapidly as affected with selection pressure. From these results, one or more of the following mechanisms may be involved in cypermethrin resistance: knock down resistance target site mutations ( $k d r)$, metabolic resistance mechanisms and/or cuticle alteration. These results were in agreement with the results of some other investigators (Brook et al., 2001; Martinez et al., 1998; Ranson et al., 2000). In Assiut region, Egypt, agricultural area is close to the field where mosquito collected for the experiment. May be using insecticides in agricultural practices play a role in selecting for resistance mechanisms in mosquitos (Antonio et al., 2008; Antonio et al., 2011; Diabate et al., 2002; Yadouleton et al., 2009). In Tanzania, A gambiae population was highly resistant to pyrethroides in the intensive use of agricultural chemicals including insecticides (Matowo et al., 2010).

\section{Conclusions}

Cypermethrin resistance level in this study from $\mathrm{G}_{0}$ to $\mathrm{G}_{15}$ representing 295.52fold resistance suggested that more than one resistance mechanism may be involved in $C x$. pipiens mosquitos. According to the present results, its highly recommend good management of using agricultural chemicals to avoid selecting kdr mutations and/or metabolic resistance mechanisms. This will help reducing mosquito control failures and improving resistance management strategies.

\section{References}

Antonio-Nkondjio, C., Atangana, J., Ndo, C., Awono-Ambene, P., Fondjo, E., Fontenille, D. and 
Simard, F. (2008), "Malaria transmission and rice cultivation in Lagdo, Northern Cameroon", Transactions of the Royal Society of Tropical Medicine and Hygiene, Vol. 102, pp. 352-359.

Antonio-Nkondjio, C., Fossog, B. T., Ndo, C., Djantio, B. M., Togouet, S. Z., Awono-Ambene, P., Costantini, C., Wondji, C. S. and Ranson, $\mathrm{H}$. (2011), "Anopheles gambiae distribution and insecticide resistance in the cities of Douala and Yaounde (Cameroon): influence of urban agriculture and pollution", Malaria Journal, Vol. 10, pp. 154-10.

Brooke, B. D., Kloke, G., Hunt, R. H., Koekemoer, L. L., Temu, E. A., Taylor, M. E., Small, G., Hemingway, J. and Coetzee, M. (2001), "Bioassay and biochemical analyses of insecticide resistance in southern African Anopheles funestus (Diptera: Culicidae)", Bulletin of Entomological Research, Vol. 91, pp. 265-272.

Chandre, F., Manguin, S., Brengues, C., Dossou-Yovo, J., Darriet, F., Diabate, A., Carnevale, P. and Guillet, P. (1999), "Current distribution of a pyrethroid resistance gene $(K d r)$ in Anopheles gambiae complex from West Africa and further evidence for reproductive isolation of the mopti form", Parassitologia, Vol. 41, pp. 319-322.

Denholm, I. and Rowland, M. W. (1992), "Tactics for Managing Pesticide
Resistance in Arthropods: Theory and Practice. Annual Review of Entomology", Vol. 37, pp. 91-112.

Diabate, A., Baldet, T., Chandre, F., Akogbeto, M., Guiguemde, T. R., Darriet, F., Brengues, C., Guillet, P., Hemingway, J., Small, G. J. and Hougard JM (2002), "The role of agricultural use of insecticides in resistance to pyrethroids in Anopheles gambiae S.L. in Burkina Faso", American Journal of Tropical Medicine and Hygiene, Vol. 67, pp. 617-622.

Elissa, N., Mouchet, J., Riviere, F., Meunier, J. Y. and Yao, K. (1993), "Resistance of Anopheles gambiae s.s. to pyrethroids in Côte d'Ivoire", Annales de la Societe Belge de Medecine Tropicale, Vol. 73 No. 4, pp. 291-294.

Fanello, C., Kolaczinski, J. H., Conway, D. J., Carnevale, P. and Curtis, C. F. (1999), "The $k d r$ pyrethroid resistance gene in Anopheles gambiae: tests of non-pyrethroid insecticides and a new detection method for the gene", Parassitologia, Vol. 41, pp. 323 326.

Georghiou, G. P. and Taylor, C. E. (1986), Factor influencing the evolution of resistance in: Pesticide resistance: strategies and tactics for management, National Academy Press, Washington, USA, pp. 157169.

Georghlou, G. P. and Lagunes-Tejeda A. 
(1991). The occurrence of resistance to pesticides in arthropods. An index of cases reported through 1989. FAO, Rome, Italy.

Guillemaud, T., Lenormand, T., Bourguet, D., Chevillon, C., Pasteur, N. and Raymond, M. (1998), "Evolution of resistance in Culex pipiens: allele replacement and changing environment", Evolution, Vol. 52, pp. 430-40.

Hemingway, I. and Ranson, H. (2000), "Insecticide resistance in insect vectors of human diseases", Annual Review of Entomology, Vol. 45, pp. 371-391.

Kuhr, R. J. and Dorough, H. W. (1976), Resistance and synergism "carbamate insecticides: Chemistry, Biochemistry and Toxicology, CRC Press Inc., USA, pp. 301.

Martinez-Torres, D., Chandre, F., Williamson, M. S., Darriet, F., Berge, J. B., Devonshire, A. L., Guillet, P., Pasteur, N. and Pauron, D. (1998), "Molecular characterization of pyrethroid knockdown resistance $(\mathrm{kdr})$ in the major malaria vector Anopheles gambiae S.S.", Insect Molecular Biology, Vol. 7, pp. 179-184.

Matowo, J., Kulkarni, M. A., Mosha, F. W., Oxborough, R. M., Kitau, J. A., Tenu, F. and Rowland, M. (2010), "Biochemical basis of permethrin resistance in Anopheles arabiensis from Lower Moshi, North-Eastern Tanzania", Malaria
Journal, Vol. 9, pp. 193-10.

Mattingly, P. F., Lloyd, E., Rozenbool, K. L., Knight, H., Laven, F. H. and Drummond, S. (1951), "The Culex pipiens complex", Trans R Ent Soc. Vol. 102, pp. 331-42.

Maxwell, C. A., Curtis, C. F., Haji, H., Kisumku, S., Thalib, A. I. and Yahya, S. A. (1990), "Control of bancroftian filariasis by integrating therapy with vector control using polystyrene beads in wet pit latrines", Transactions of The Royal Society of Tropical Medicine and Hygiene, Vol. 84, pp. 709-14.

Ranson, H., Jensen, B., Vulule, J. M., Wang, X., Hemingway, J. and Collins, F. H. (2000), "Identification of a point mutation in the voltagegated sodium channel gene of Kenyan Anopheles gambiae associated with resistance to DDT and pyrethroids", Insect Molecular Biology, Vol. 9, pp. 491497.

Raymond, M. and Marquine, M. (1994), "Evolution of insecticide resistance in Culex pipiens populations: the Corsican paradox", Journal of Evolutionary Biology, Vol. 7, pp. 315-337.

Robertson, J. L., Preisler, H. K., Russel, R. and Savin, N. E., (2007), Bioassays with Arthropods, $2^{\text {nd }}$ revised edition. CRC Press, Taylor $\&$ Francis, pp. 224.

Subra, R. (1981), "Biology and control of 
Culex pipiens quinquefasciatus with special reference to Africa", Insect Science and Its Application, Vol. 1, pp. 319-338.

WHO (1981), Instruction for determining the susceptibility or resistance of mosquito larvae to insecticides, WHO-VBC 81-807, Geneva, Switzerland, pp. 1-6.

WHO (2013), World Malaria Report 2013, WHO, Geneva, Switzerland.

WHO (2014), Guidance for Countries on Combining Indoor Residual Spraying and Long-Lasting Insecticidal Nets, WHO, Geneva, Switzerland.
Yadouleton, A. W. M., Asidi, A., Djouaka, R. F., Braima, J., Agossou, C. D. and Akogbeto, M. C. (2009), "Development of vegetable farming: a cause of the emergence of insecticide resistance in populations of Anopheles gambiae in urban areas of Benin", Malaria Journal, Vol. 8, pp. 103-110. 